\title{
NARCotráfico Y DisOluCIÓN FAMILIAR EN HIJOS DE LA NIEVE (2000) DE José Libardo Porras*
}

\author{
DRUG TRAFFICKING AND FAMILY DISSOLUTION IN \\ HiJOS DE LA NIEVE (2000) By José Libardo PorRas
}

Daniel Felipe Osorio Correa ${ }^{1}$

\footnotetext{
* Cómo citar este artículo: Osorio Correa, D. F. (2020). Narcotráfico y disolución familiar en Hijos de la nieve (2000) de José Libardo Porras. Estudios de Literatura Colombiana 47, pp. 129-150. DOI: http://doi.org/10.17533/ udea.elc.n $47 \mathrm{a} 07$

${ }^{1}$ https://orcid.org/0000-0002-9800-5138 feliposo10@gmail.com Instituto de formación docente Salomé Ureña, República Dominicana
}

Editores: Andrés Vergara Aguirre, Christian Benavides Martínez, Valentina Noreña Gómez

Recibido: 25.01 .2020

Aprobado: 27.04.2020

Publicado: 23.06.2020

Copyright: (2020 Estudios de Literatura Colombiana. Este es un artículo de acceso abierto distribuido bajo los términos de la Licencia Creative Commons AtribuciónNo comercial - Compartir igual 4.0 Internacional
Resumen: la novela Hijos de la nieve tematiza las consecuencias del narcotráfico en una familia de extracción popular de Medellín en los años 80. El narcotráfico, por un lado, degrada axiológicamente al hijo mayor, Capeto, y, por otro lado, ocasiona la inevitable disolución del tejido familiar. Propongo que la novela construye una alegoría entre sociedad y narcotráfico, en el que cada miembro de la familia González representa a un actor social de la época.

Palabras clave: descomposición familiar; Hijos de la nieve; Medellín; narcotráfico; sociocrítica.

\begin{abstract}
The novel Hijos de la nieve deals with the consequences of drug trafficking in a low income family in Medellin during the 1980's. Drug trafficking, on one hand, axiologically degrades the eldest son, Capeto, and on the other, causes the inevitable dissolution of the family unit. I propose that the novel constructs an allegory between society and drug trafficking, in which each member of the González family represents a social "actor" of the time.
\end{abstract}

Keywords: family decomposition; Hijos de la nieve; Medellin; drug trafficking; sociological criticism. 


\section{Introducción}

Aunque resulte difícil de creer que muchos jóvenes de las barriadas de Latinoamérica siguen idolatrando la figura de Pablo Escobar y anhelando seguir sus pasos, dado que el periodismo ha contado las atrocidades que él y su banda de criminales hicieron en la década de los 80 y principios de los 90, se puede constatar fácilmente que permanece la fascinación por el "Capo de capos" entre muchos de estos adolescentes precarizados. Ana Cristina Uribe (2018), en Medellin a oscuras, transcribe algunos fragmentos de la entrevista que realizan en el documental Narconovelas (por etnológica), del 2014, a jóvenes de barrios marginales que ven esas producciones:

¿En esas escenas ustedes a quién le hacían fuerza? - pregunta el hombre.

- Al capo, obvio - responde un coro de mínimo tres niños.

-Yo no sé. Porque uno desde el principio empieza con la idea de que el capo es el bueno... entonces uno ya desde el principio... el capo ya tiene las de ganar, el gobernante $[\ldots]$.

—¿Y qué es lo bueno de ser Pablo Escobar? — vuelve a preguntar el hombre.

- Que él tiene muchas fincas y él se puede esconder.

- $\mathrm{Y}$ esas fincas son muy secretas.

-Y él tiene mucho dinero. Y él contrata amigos.

-Y él tiene muchos amigos, muchas armas.

-Él fue malo, pero hizo muchas cosas buenas por Medellín.

-Él fue malo por el hermano.

-Él ayudó a los pobres (pp. I4-15).

Las explicaciones al hecho de que persista una imagen positiva del más sanguinario narcotraficante de la historia de Colombia son múltiples. Se pueden señalar algunas: la proliferación de producciones culturales que reproducen en esta figura al hombre astuto que supo conseguir dinero y fue capaz incluso de desafiar a un Estado; la representación social que sigue transitando en las barriadas de Medellín y que lo presenta como el padre, hijo y hermano amoroso, y el filántropo financiador de barrios, hacedor de iglesias y canchas de fútbol; la continuación de las condiciones de desigualdad y de precarización de los niños y jóvenes de estos barrios, que los lleva 
a pensar en imitar el camino de Escobar para obtener una vida soñada. Contrastar dichas representaciones para entender lo ocurrido y para no seguir reproduciendo pequeños narcos y sicarios es el espíritu que orienta muchas producciones culturales que entienden que caer en la exotización de la vida del delincuente o trivializar los ocurrido puede ser redituable para el artista o productor, pero no permite entender un fenómeno tan complejo que entroncó en todas las instituciones y espacios de sociabilidad de los colombianos y que sigue determinando nuestra historia.

En la literatura, la re-creación de la figura del narcotraficante y de los efectos producidos por las estructuras criminales que se nutren económicamente de este negocio ha generado un corpus que se ha denominado literatura del narcotráfico, debido al anclaje temático de estos textos literarios (cuentos y novelas) con sus referentes sociohistóricos. No se incluyen los textos que abordan la drogadicción o la criminalidad, y tampoco aquellos escritos por narcotraficantes, en calidad de testimonio periodístico y no de ficción, pues no profundizan en el fenómeno social del narcotráfico. Este corpus literario ha aumentado en los últimos años en Colombia y algunos de los escritores más reconocidos del país como Laura Restrepo, Gustavo Álvarez Gardeazábal, Juan Gabriel Vázquez, Héctor Abad Faciolince, Darío Jaramillo Agudelo, entre otros, lo han convertido en eje de sus producciones. De la misma manera, la crítica literaria se ha ocupado de valorar recientemente estos relatos, superando un prejuicio de vieja data que asume que tematizar los escenarios de violencia es una manera de reproducirlos, de apologizarlos.

Un escritor que ha abordado el tema del narcotráfico en sus producciones narrativas es el antioqueño José Libardo Porras (1959-2019), quien produjo una nutrida obra compuesta por novelas, libros de cuentos y poemarios. Algunos de estos libros fueron premiados en concursos literarios nacionales: en 1996 ganó dos premios. De un lado, el Premio Nacional de Literatura, en la categoría de cuento, por el libro Historias de la cárcel de Bellavista; por otro lado, el Primer lugar en el Concurso Literario Cámara de Comercio de Medellín por Seis historias de amor, todas edificantes. E1 Premio Novela Inédita para Autor con Trayectoria lo ganaría dos veces: en el 2015 con la novela Adentro, una biena y en el 2018 con la novela Lucky. Fuera de ellos se encuentra Hijos de la nieve (2000), el séptimo de doce libros que publicó y, aunque no ha ganado premios en concursos literarios, es probablemente el más conocido del autor. 
Hijos de la nieve hace parte del corpus literario sobre el narcotráfico que tematiza el flagelo en la región de Antioquia. Este corpus está formado por novelas como Cartas cruzadas (1995), En vozbaja (1999) y Angosta (2003), las cuales “coinciden en hacer una sanción negativa del negocio y de la actitud de beneficio y connivencia de la sociedad respecto de los narcotraficantes. El narcotráfico aparece señalado directamente como causa fundamental del disloque social y la pérdida de valores" (Osorio, 2014, p.179). La actitud de connivencia que señala Osorio es el eje fundamental de la novela de Porras que, además de hacer una descripción pormenorizada del circuito de la droga, profundiza en la relación que sostuvo la sociedad con el narcotráfico en el momento en el que empezó a irrigar la debilitada economía de la ciudad.

Para precisar la interpretación que orienta la novela utilizaré la noción de medio ideológico que propone Bajtín en El método formal de los estudios literarios. El autor ruso reconoce la literatura como una de las formas de las ideologías, no como el vivo reflejo de la realidad. Esto quiere decir que cualquier novela, perteneciente a cualquier época, no representa el funcionamiento real de los valores, las interacciones sociales y económicas que opera en dicho contexto, sino una imagen refractada de la vida, una percepción ideológica de un solo sujeto: "La literatura 'refleja' al hombre, su vida y su destino, su mundo interior, siempre dentro de un horizonte ideológico; allí todo se realiza en el mundo de los parámetros y valores ideológicos” (Bajtín, 1994, p. 60).

Para hablarnos del medio ideológico, Bajtín va a plantear la noción de ideologema, llamada también por el autor "producto ideológico". Esta puede ser entendida como la materialización de una orientación ideológica del sujeto. Orientación que está determinada por el entrecruzamiento de las distintas formaciones ideológicas que atraviesan su formación social. En la literatura "Solo al plasmarse ideológicamente, al refractarse por el prisma ideológico, la vida como conjunto de determinadas acciones se convierte en argumento, tema, motivo. Una realidad aún no refractada ideológicamente, cruda, por decirlo así, no puede formar parte de un contenido literario"(p.61). En este sentido, la tarea para el investigador de los estudios literarios, al trabajar con ideologemas, consiste en determinar la orientación ideológica de determinado texto, y la lectura de ciertas coordenadas históricas particulares. Establecer, en síntesis, cuál es el horizonte ideológico de su creador. ${ }^{1}$

1 En el análisis que hago sobre la novela, construyo el ideologema narcotráfico en función de identificar la orientación ideológica que ofrece la novela sobre la relación entre narcotráfico y sociedad en el contexto paisa. 
Además de expresar la disolución familiar que ocasiona la inmersión de una familia de extracción humilde en el mundo del narcotráfico, Hijos de la nieve presenta el circuito de la cocaína en Colombia: Capeto empieza como mula de pasta de coca y, a medida que va ganando experiencia, asciende hasta conseguir una pequeña fortuna que le permite dedicarse a gerenciar su propia empresa. Con un rigor casi periodístico, la novela informa los insumos y las cantidades con las que se procesa la coca, las formas en las que se empaca y se distribuye, las empresas que sirven de fachadas para lavar el dinero de la droga, los intermediarios en cada una de esas fases, la corrupción de las instituciones estatales, entre otras consideraciones asociadas al negocio.

A pesar de las bondades señaladas en el párrafo anterior, la novela ha sido poco estudiada y los críticos que se han ocupado de ella lo han hecho como parte de trabajos más amplios en torno del corpus literario del narcotráfico en Colombia. En Cuando llovió dinero en Macondo: literatura y narcotráfico en Colombia y en México, Alberto Fonseca (2009) analiza la forma en la que el autor construye el relato, a partir de "la relación existente entre el presente de la narración (monólogos) y el pasado de la historia de Capeto y su progreso en la mafia (narrador en tercera persona)" (p. 116). Fonseca señala que esta estrategia narrativa permite que "nos acerquemos a diferentes puntos de vista sobre la caída familiar" (p. 116). Por otra parte, el crítico concluye que las distintas formas de hablar de los personajes de la novela generan una "heteroglosia" textual que expresa la manera en la que distintos sectores de la sociedad antioqueña se relacionaron con el narcotráfico. Por su parte, en El narcotráfico en la novela colombiana, Óscar Osorio (2014) indaga en la lectura del mundo que ofrece la novela. Para este crítico, "La novela se concentra en el proceso de degradación de los integrantes de una familia y, a través de ella, se muestra el proceso de descomposición de la sociedad toda" (pp. 125-126). A su juicio, el final trágico de los personajes de la novela orienta una lectura sancionadora de la corrupción del tejido social antioqueño como consecuencia del narcotráfico. El punto de vista que orienta dicha valoración es, señala Osorio, "el de la sociedad tradicional paisa" (p. 126).

Ambos críticos coinciden en señalar que la novela expresa la ruptura del núcleo de la familia tradicional antioqueña como consecuencia del ingreso al negocio de uno de sus miembros. Participo de esa apreciación, pero quiero profundizar en la clave alegórica que propone la novela, que es la de una sociedad que permitió el ingreso 
del narcotráfico. Para ello, divido la novela en tres momentos que dan cuenta de la propuesta ideológica que la orienta: primero, el preingreso de Capeto al narcotráfico, "ritual" que explora el panorama social que atraviesa un joven de bajos recursos en una sociedad estancada; segundo, el ingreso a la redes del narcotráfico y la inevitable degradación axiológica de su subjetividad y la de su familia; tercero, el "castigo" y arrepentimiento de los miembros de la familia, lo que señalaría, siguiendo la clave alegórica, las transformaciones que provoca el narcotráfico al tejido social antioqueño.

\section{Preingreso al mundo del narcotráfico}

El narrador de la novela es omnisciente y heterodiegético, y el tiempo de la narración es simultáneo con el tiempo de la historia. Tales decisiones estéticas hacen que el lector sea "testigo" de la inserción del protagonista en el mundo del narcotráfico y el progresivo deterioro tanto de su axiología como la de su familia que se deriva de esta decisión. Los primeros capítulos de la novela presentan la situación vital de Capeto. Él es un adulto joven que, como el resto de su familia, se dedica de tiempo completo a la empresa de empacar pasas, con lo que apenas se sostiene la economía del hogar. Capeto es un joven tímido e imaginativo que se habla a sí mismo a través de las cosas con las que se va encontrando:

Desde una mesa interior en El Chócolo De la 70, ante un vaso de cerveza y un cenicero, ve pasar a los estudiantes de La Bolivariana. Dos peludos con carpeta en una mano y regla $\mathrm{T}$ en la otra se afanan a clase; los siguen una pareja de angelitos abrazados, ella de minifalda y blusa ombliguera, una nalga arriba otra abajo una nalga arriba otra abajo al caminar, él con jean y tenis desgastados y sucios. A estos les luce todo, hasta la mugre, le dice un laurel que crece en la acera del frente y el viento agita. En sentido contrario, tres bellezas fugadas de la pantalla de la tele o de una revista, luego otras dos y a tres o cuatro pasos, uno con cara de profesor o de empleado bancario, que al fin de cuentas se confunden [...] Capeto, le informa una veranera raquitica que la sombra de un laurel achicopala. Tu vida está a años luz de la vida gorda de aventuras y encantos que a esos estudiantes de la Bolivariana aguarda. Sos un pintado en la pared, un chichipato, Capeto. Se ve encorvado sobre la mesa de trabajo llenando cajitas de uvas pasas infinitamente mientras ellos construyen edificios o salvan vidas (Porras, 2000, p. 9).2 condición de pobreza que, como se indicará más adelante, es una expresión de la mediocridad en la realización vital del hombre de esta región. 
Capeto es un personaje con el ego socavado por la conciencia de pertenecer a una clase social con una mínima posibilidad de movilidad económica y de ascenso social. Dado que reprobó el examen de ingreso a la universidad pública, no tiene la posibilidad de escalar en la pirámide social a través del estudio:

\begin{abstract}
[...] igual a los que planean la manera de gastar e invertir el gordo del Sorteo Extraordinario de Navidad antes de ganarlo, e incluso siguen haciéndolo después de declarado el ganador, fantasea: una parte de su sangre le dice que aún es posible ser feliz con una muchacha como cualquiera de esas: vos médico y ella abogada o ingeniera o arquitecta, con varios hijos, tres o cuatro, rubiecitos, en una casona entre los bosques del Poblado (p. Io).
\end{abstract}

Sin embargo, él mismo expresa su escepticismo, incluso, con respecto a la relación causal entre egresar de la universidad y conseguir empleo como profesional. Capeto piensa: “¿Para qué ser profesional, para terminar de taxista?” (p. 9).

La sociedad que se bosqueja en esta primera parte de la novela es desigual, no garantiza el derecho a la educación ni posibilidades de ascenso social para los jóvenes que pertenecen a las comunas. Esta es la misma situación que atraviesa Medellín en los años 80. Son varias las causas que explican la peculiaridad social de la ciudad. Por una parte, atraviesa una compleja coyuntura socioeconómica desde inicios de la década de los 70 que se profundizará en los años 80 . Una de las razones está asociada al contexto económico internacional:

Los grandes centros latinoamericanos de difusión del modelo de industrialización sustitutiva y de sus doctrinas, Argentina, Brasil, México y Chile, empezaban a experimentar una profunda crisis del modelo que, en el contexto mundial del shock petrolero y el aumento internacional de las tasas de interés, llevaría a los pocos años a la crisis de la deuda externa y al consiguiente "ajuste fiscal" (Reina Echeverry, 1992, p. 58 ).

Además, en el ámbito regional el clima de recesión económica se agudizó más por el retraso infraestructural que vivía la ciudad y que se debía, en gran medida, a la ausencia de capitales extranjeros en la economía local. La que en alguna ocasión había llevado orgullosa el título de ser "la ciudad industrial de Colombia" se hallaba atrasada en el proyecto de convertirse en una metrópoli con respecto de Cali y Bogotá. 
La diferencia entre Capeto y los jóvenes estudiantes a los que observa es absoluta. $\mathrm{Su}$ diferencia frente a esos otros, que "les luce todo, hasta la mugre", simboliza la progresiva escisión de Medellín en dos ciudades completamente antitéticas: la del plan y la de la loma, la urbana y la de inmigrantes campesinos de la comuna. En este sentido, el texto recalca que el origen de la familia de Capeto es rural:

Capeto, como si leyera un periódico de ayer, lo oye repetir su video sin fin sobre las maravillas del éxito. Recuerda al campechano de Támesis que, cuenta su padre, a los políticos que iban a prometer y a engatusar se les arrimaba preguntándoles: ¿Y qué hay pa yo, dotor? Sonríe (Porras, 2000, p. 8).

La memoria de vieja data que se presenta en la novela con el recurso del recuerdo de Capeto hace alusión a la ciudad que se convierte desde finales de los cuarenta en el epicentro de la migración del campo a la ciudad en la región Andina. Miles de familias campesinas llegaron por la centralidad de la región con respecto a los lugares donde se concentró la Violencia y por el auge de la industria textil en los 50. Sobre la época de la Violencia en Colombia, Marco Palacios (2002) define este periodo como "unos 20 años de crimen e impunidad facilitados por el sectarismo (1945-1965) que dislocó la vida de decenas de familias y comunidades [y que] en las regiones andinas y en los llanos orientales, un 40\% de la población padeció directa o indirectamente su impacto" (p. 193).

La ciudad a la que llegaron estas personas no las incluyó en su proyecto y, por el contrario, las marginalizó. Además de los contrastes geográficos señalados, la diferencia se fragua en la forma de hablar, pues una emplea "bien" el español mientras la otra lo hace de manera "incorrecta"; y bajo una supuesta diferencia racial, la una se asume como mestiza y la otra como blanca. Capeto ha introyectado esa idea y asume un blanqueamiento racial a partir de la procreación con una persona perteneciente a esa otra Medellín. El dispositivo ideológico que opera en este planteamiento indica que procrearse con una persona de la otra Medellín equivale a blanquearse.

Tales procesos de exclusión y de marginalidad, de violencias residuales que traen consigo las familias de desplazados por la violencia, sumados a la falta de acceso a derechos básicos de salud y educación, van a profundizar la crisis de la ciudad desde 
la década del 60. A la violencia y las exclusiones sociales referidas hay que sumar el desencanto de estos jóvenes por una ciudad que no los convoca política ni culturalmente. En el plano político local, la desaparición de los patriarcas políticos de la época de la Violencia coincidió con el desmonte del Frente Nacional (1958-1974). La ausencia de liderazgo en los dos partidos tradicionales fue suplida por una nueva generación de tecnócratas clientelistas que ocasionaron el desencanto de los adeptos de ambos partidos. De igual manera, la izquierda en Colombia se había fragmentado desde finales de los años 60 y no había logrado capitalizar la falta de credibilidad en los partidos tradicionales. E1 resquebrajamiento de la política local se puede ver traducido en las altas tasas de abstencionismo electoral que reinaron durante los años setenta.

Por otra parte, en el ámbito cultural, el proyecto de la antioqueñidad asociado a la idea del campesino cafetero ya no seducía a las nuevas generaciones que pedían a gritos nuevos modelos culturales. Aunque movimientos artísticos como el punk y el rock oxigenaron la escena cultural de la ciudad, la actitud que predominó entre los grupos de élite fue, de acuerdo con Salazar (2012), la "afirmación de lo pasado y el bloqueo a las expresiones de modernidad que intentaban ganar un reconocimiento social en el espacio urbano" (p. 31). Para este autor, el enclaustramiento cultural contribuyó al "agravamiento de la problemática urbana en ebullición y favoreció la emergencia de nuevos parapoderes y contrapoderes en las dos décadas posteriores" (p. 31). Lo anterior favoreció la aparición y el prestigio de un nuevo actor social en la ciudad: el "traqueto".

En ese contexto de escasas oportunidades en el que se ubica el cronotopo de la historia, intempestivamente jóvenes precarizados empiezan a presumir objetos costosos que no tienen forma de adquirir por la vía de la legalidad. Capeto lo atestigua cada que lo visita su amigo Nelson, antiguo compañero de colegio que "En una Yamaha 750 rugidora se apea con seguridad, dueño de sí, orgulloso de su máquina” (Porras, 2000, p. 10).

El texto expresa la disyuntiva de Capeto. Por un lado, le espera una vida honesta, pero sin posibilidad de promoción social y sin acceso a estos bienes. Por el otro, una vida con posesión de estos bienes, pero del lado de la ilegalidad. A la situación social esbozada se debe sumar la presión propia de la lógica consumista de un mundo globalizado en el que vales por lo que tienes. De acuerdo con Erna von der Walde 
(2000), la Medellín de los años 80 "es apenas un escenario de lo que se anuncia para otros muchos lugares del planeta en tiempos de globalización: el vaciamiento de sentidos, el cierre de horizontes, el desencanto en un mundo que predica el consumo como única forma de pertenencia ciudadana” (p. 225). Esta pulsión desbordada por el consumo se expresa siempre en unas marcas particulares, que a su vez construyen un estereotipo. Aunque en Hijos de la nieve no se profundiza en estas marcas, en La virgen de los sicarios, de Fernando Vallejo (1994), el joven sicario Wilmar le pone nombre propio a sus deseos materiales: "quería unos tenis marca Reebock y unos jeans Paco Ravanne. Camisas Ocean Pacific y ropa interior Kelvin Klein. Una moto Honda, un jeep Mazda, un equipo de sonido láser y una nevera para la mamá”(p. 91).

De regreso con Porras, la focalización del narrador omnisciente que detalla el sentir de Capeto es fundamental para expresar las motivaciones, miedos y dudas del personaje principal. Esta etapa se caracteriza por la duda del protagonista entre seguir siendo pobre toda la vida o ingresar al mundo del narcotráfico y vivir una vida como los jóvenes que pertenecen a la otra Medellín. La disyuntiva de Capeto revela una azarosa incertidumbre en el personaje y complica su sistema axiológico o sus valores individuales, al tiempo que los familiares. Ser pobre en tanto signo de desprestigio social y exclusión de clase; ser mafioso, desafiar el orden hegemónico y situarse respecto a una clase social emergente. Aunque el ejemplo de sus padres como personas laboriosas y honestas lo invitan a permanecer en la legalidad, la seguridad de seguir siendo un "chichipato" toda la vida horada el ego del personaje. En su emblemático texto La familia en Colombia. Trasfondo histórico, Virginia Gutiérrez de Pineda (1994) explica la importancia que tiene el dinero en el hombre antioqueño como máxima realización vital:

El capital financiero activo y crediticio, que cada individuo puede tener en su haber, conforma el denominador en que cristaliza su realización de ser adulto y el indicador que lo sitúa dentro de su comunidad. Los demás factores son meras contingencias subordinadas, porque solo cuenta para identificarlo y para situarlo lo que ha sido capaz de crear o de poseer económicamente y la manera como lo vierte dentro de su sociedad (p. 40\%).

Siguiendo a la autora, no conseguir riqueza equivale en este intrincado complejo sociocultural de la "Montaña" a una subrealización del proyecto de vida del adulto. Es importante agregar que en el hombre antioqueño existe cierta flexibilidad ética 
frente a la forma de granjearse los recursos. Esto se revela con singular potencia en los refranes "hay que intentar ser rico de manera legal, pero si no se puede, hay que ser rico como sea" y "Disponer de dinero es lo importante, propio o ajeno es secundario". Gutiérrez de Pineda (1994) hace alusión a esa condición arraigada el ethos del hombre antioqueño:

En esta simbiosis de la religión y de la economía, hallamos un rasgo más de interrelación entre las dos: existe la creencia común de que la moral es elástica en la obtención del triunfo en los negocios o actividades productivas de cada individuo. Una gran plasticidad de acción se permite en la ética económica. Así como en el mundo de la economía no hay en la Montaña restricción o limitación de actividades lucrativas, tampoco existen inhibiciones en el comportamiento que se debe seguir con el objeto de alcanzar el éxito monetario. Encuestando a este respecto se observa en la conciencia popular una amplísima elasticidad, hasta el punto de que los canales de realización de la meta económica pueden adquirir la más variada y compleja expresión en función de los fines buscados. Mientras la moral religiosa se focaliza más en el campo de la ética familiar, relacionada con la acción productiva ninguna o escasas inhibiciones deterioran o anulan su libre acción. Y esta libertad, que no solo está en relación con la justicia divina, halla, como es lógico suponer, una amplia gratificación en la cultura: en la economía antioqueña la obtención de la meta legitima los medios (p. 386).

Recapitulando, la importancia de la adquisición de dinero y la flexibilidad ética frente al origen de los recursos constituyen un terreno fértil para el ingreso triunfal del narcotráfico en la sociedad antioqueña. El preingreso al mundo del narcotráfico expresa la situación de una ciudad en la que pululan jóvenes como Capeto: precarizados, y disminuidos en su ego por el efecto de diversos mecanismos de exclusión social. Estos jóvenes encuentran en el narcotráfico la posibilidad de acceder a bienes de consumo globales que prometen otorgar un sentido a la experiencia vital. En la siguiente etapa se indaga en las consecuencias del ingreso de Capeto a una red del narcotráfico. Especialmente, se expresa la degradación axiológica personal y familiar progresiva, además de la sustitución de los valores que sustentaban el núcleo familiar.

\section{Inmersión en el narcotráfico: descomposición axiológica y disolución familiar}

El ingreso de Capeto al mundo del narcotráfico genera rechazo por parte de Genaro, su padre y, por tanto, "jefe de hogar", en consonancia con la estructura familiar tradicional 
antioqueña. Cuando este se entera del origen del dinero que empieza a abundar en la casa, le reprocha a su esposa, pero no se atreve a confrontar a su hijo. El padre se lamenta: “-Yo sabía, mija, que lo de ese muchacho no era nada bueno. Quién sabe qué clase de aves serán el tal Villa y el tal Gilberto Álvarez. ¡Y el Carlos Alberto metido con ellos!” (Porras, 2000, p. 45). Luego, cuando sospecha que el dinero ha ingresado a la casa con el beneplácito de su esposa, le reclama: “-Mija, ¿usted sabía?... Contésteme: ¿usted sabía? Hay un silencio espinoso. Ella asiente” (p. 45). Esa certidumbre no se canaliza en una oposición al dinero, más bien se expresa a modo de pataleta hacia su esposa, a quien recrimina por aceptar el dinero mal habido: “-Yo no quiero saber nada de esa plata que él consigue. ¡Esa plata es maldita! ¡Es el cagajón del diablo! (p. 87).

Las citas anteriores expresan la desaprobación que el jefe del hogar hace con relación al dinero del narcotráfico. El "pecado" de Genaro consiste en lamentarse con su esposa en lugar de ofrecer resistencia directa a Capeto. Genaro representa la sociedad antioqueña que rechaza moralmente el ingreso del dinero del narcotráfico a la sociedad antioqueña, pero que en un principio no le hace frente a dicho lucro y luego se ve ampliamente superado por la magnitud del fenómeno. De esta manera, Genaro encarna los valores (honestidad, reivindicación del esfuerzo inherente al trabajo) que se van a sustituir por los que promueve el narcotráfico.

Luzmila, la madre de Capeto, acepta el ingreso de la economía de la droga en la casa y, aunque ofrece un tibio rechazo moral, prefiere hacerse la de la "vista gorda". Esta situación se puede observar cuando Juan le pregunta reiteradamente a su hermano, Capeto, por un boleto de avión que encuentra en el cajón de su habitación. "-Por qué vas tanto a Puerto Asís? — pregunta Juan. La madre piensa: ¡OOtra vez el bocaza!”(p.43). En otro momento, la madre, que tiene como función en la estructura social antioqueña administrar la economía del hogar, recibe con agrado el dinero que le entrega Capeto y que supera ampliamente el del otrora negocio familiar de empacar pasas:

Doña Luzmila disfruta desentenderse de las culebras. Antes, al juntarse pensiones de colegios, servicios públicos y arriendo, como si de esos pagos dependiera la vida de cada uno de sus hijos, arañaba cuanto peso podía arañar a sus necesidades; la aterrorizaba el solo riesgo de incumplir, pues compartía con su esposo la idea de que la mayor fortuna es un buen crédito. Ahora, nunca falta lo preciso y más, y después de pagar se siente como si hubiera acabado de almorzar y pudiera darse una siestita (Porras, 2000, p. 47). 
Luzmila representa la sociedad tradicional que no opone mayor resistencia al narcotráfico y que prefiere el recurso de la omisión, del silencio, del ocultamiento - sobre todo por el temor a la reacción de Genaro-, pues disfruta del alivio a las afugias económicas cotidianas. Coincide el caso de Luzmila con el de la mamá de Pablo Escobar, que en entrevista con Alonso Salazar (2012) señala que

\begin{abstract}
Pablollevaba una pequeña temporada matriculado en Contaduría en la Universidad Autónoma hasta que, preocupado por la pobreza de la familia le notificó una noche a doña Hermilda que abandonaría los estudios: "Yo le agradecí su intención de colaborarme - dice doña Hermilda -; no me pareció mal que le encontrara gusto al dinero, porque si uno no mantiene un peso en el bolsillo, se mantiene aburrido, triste, cabizbajo, no le encuentra salida a la vida. Y Pablo, con la enseñanza aprendida, solía decir: yo pobre no me muero, para mí primero Dios y después la plata" (Salazar, 2012, p. 32).
\end{abstract}

Luzmila en la ficción y Hermilda en la realidad expresan la aceptación que las mujeres hacen del dinero ilegal como propulsor de la economía hogareña, pues son estas las encargadas de administrar todo lo concerniente con el hogar. Su entrada a la estructura más importante de la sociedad antioqueña simboliza, por lo tanto, el ingreso al conjunto de la sociedad.

Con los hermanos menores de Capeto va a pasar algo distinto. Estos celebran sin ningún tapujo de orden moral el ingreso de Capeto al mundo del narcotráfico. Reconocen en este un camino expedito para superar las condiciones económicas en las que viven. Adriana y Juan representan nuevos actores sociales que se benefician abiertamente del dinero del narcotráfico, ella como esposa de un mafioso y él como parte de la pirámide delincuencial que crea el narcotráfico. Con relación a la sustitución de valores, una de las consecuencias directas de este dinero en la familia es la renuncia de los dos a la lógica del esfuerzo asociado al trabajo honesto. Cuando el dinero se hace evidente, Adriana y Juan empiezan a hacer resistencia al trabajo de empacar pasas: “¿Cuándo podremos dejar esa trabajadera?” (p. 45), “¿Cuándo seremos ricos?" (p. 45). Pronto, celebran las consecuencias de este dinero en la familia: "No necesitamos trabajar" (p. 46), “Nos llegaron las vacas gordas" (p. 46), "Este trabajo de Capeto es muy chévere - comenta Adriana- Al menos puede pagarnos todo sin problemas" (p. 47). 
Esta etapa se caracteriza por la reconfiguración de la figura del "Jefe de hogar". Superado como fuente de ingresos, Genaro pierde terreno con respecto a la función tradicional del padre en la estructura social antioqueña, que es la de soportar la economía hogareña, debido al dinero que empieza a llegar de manera alternativa, pero que rápidamente se convierte en la principal fuente de ingresos que irriga la casa de los González. Para Gutiérrez Pineda (1994), el contrato de facto de las mujeres de la Montaña hace que, cuando se casan, "el marido [sea quien] responderá económica y socialmente por su esposa, constituyendo complementariamente una fuerza nueva de apoyo al hogar primario de la misma" (p. 467). En este orden de ideas, cuando se desplaza al marido como la fuente de ingresos que soporta la economía hogareña, pierde su función en la estructura familiar:

Se va. Tira la puerta al salir. Ella [Luzmila] saca la cabeza de entre las cobijas, sus ojos llorosos, y apaga la luz. Esposa enamorada, ve en ese conflicto el origen de la ruptura definitiva. Se fue; no volveré a verlo. Se lo figura recorriendo las calles, huyendo de frío, huyendo de ella y sus hijos (Porras, 2000, p. 45).

Desplazado Genaro, Capeto se erige, entonces, como la nueva figura de autoridad. Por lo tanto, renuncia a la subordinación nominal:

\begin{abstract}
A sus padres, los hombres ni siquiera les decían papá y mamá sino apá y amá. - Apá esto. Amálo otro. Decirles papá y mamá o papi y mami, como Adriana, lo consideraban un mimo inconveniente para su condición humilde. En ese rústico apá o amá sus hijos les manifestaban su amor y les reconocían una dignidad de seres superiores y ellos lo sabían. Capeto deja de decirles apá y amá; los llama por sus nombres: Genaro y Luzmila. - Luzmila traéme esto, Luzmila tráeme lo otro (p. 47).
\end{abstract}

En concordancia con lo anterior, hay una sustitución de una economía familiar que dirige el padre y en la que participan todos por una economía que proviene de una sola fuente ilegal. Este cambio de modelo económico alegoriza lo ocurrido en la sociedad de Medellín cuando "La industria, ante la competencia del contrabando y la obsolescencia tecnológica, entró en decadencia, y miles de obreros fueron arrojados a las calles" (Salazar y Jaramillo, 1992, p. 77), y el narcotráfico se convierte en la forma en la que se aceita la estancada economía de la ciudad que se profundiza en las comunas por las condiciones de base que ya se han señalado. Esto quiere decir que 
el dinero del narcotráfico que llega a las comunas a partir de múltiples interacciones sociales (subculturas del narcotráfico, regalos y donaciones del narco a particulares o instituciones, lavado de dinero, por ejemplo) se constituye en uno de los ingresos principales de las familias de las comunas de la ciudad.

Por otra parte, el ascenso de Capeto en el negocio del narcotráfico es directamente proporcional con su degradación axiológica. Revestido con un nuevo sistema de valores que le permite habitar ese violento mundo - que está asociado al detrimento del valor de la vida, de la honestidad y del esfuerzo, y a la consecución de dinero, el despilfarro y la ostentación-, no tiene problema en instalar un laboratorio para la producción de coca en su casa e ingresar a su hermano en la estructura del negocio como "cocinero", so riesgo de muerte por la manipulación de los químicos usados para la elaboración de la pasta de coca: “¿No sabés lo peligrosa que es esa maricada? —le advierte Nelson- En cualquier momento una explosión y no queda ni mierda... ¿Y quién te va a ayudar? Capeto señala con la cabeza a Juan” (Porras, 2000, p. 47).

El valor principal que pierde el protagonista, como se advierte en la cita anterior, es el de la vida. Esto se manifiesta en diferentes momentos del texto. En muy poco tiempo de haber ingresado en la estructura criminal, por venganza, dispone del asesinato de cuatro federales que habían retenido a su hermano y que le habían cobrado un rescate de 500000 pesos: "Aparte de pagar, no tengo que mover ni un dedo. Óscar se encargará" (p. 67).En ese momento aún se confronta éticamente: "Su deseo era algún día dejar esa vida de pobre, no dedicarse a disponer asesinatos” (p. 67). Sin embargo, rápidamente resuelve su cuestionamiento con un refrán que indica las barreras morales que ha transgredido: "Todos tenemos que morir; nadie se muere en la víspera" (p. 67). Para Capeto, la muerte de cuatro seres humanos es un precio justo por haberlo chantajeado, pues el prestigio del maleante está fuertemente asociado con no "dejarse" de los otros. En esta lógica de la axiología, la idea del narcotraficante como el que "pega más duro", disuelve cualquier posibilidad de mesura, empatía y respeto por la vida de los otros.

Esta trasmutación de valores lo vuelve un tipo violento y agresivo, que amenaza con matar a un camarero porque no le consigue un whisky: "-Yo soy dueño de su vida, yo dispongo de su vida, si quisiera podría matarlo - le hundía el cañón del arma en la sien-. Deme un whisky" (p. 90). De la misma manera, se regocija con las historias de sangre. El lenguaje, que desvela las estructuras profundas del ser humano, manifiesta 
ese nuevo ethos del personaje. Al contar la muerte de un mafioso a Juan, Adriana y Luzmila, "no sólo los impresiona el relato en sí, sino también la manera de contarlo: sus palabras fascinadas revelan encanto con la imagen sangrienta. Una situación que en otro tiempo podría descomponerle el estómago, ahora lo regocija” (p. 75).

No solo Capeto se degrada axiológicamente. Con él como proveedor de dinero y, por tanto, ejemplo de ser humano exitoso desde la perspectiva de un mundo alienado a lo material, Juan y Adriana pierden los valores inculcados por sus padres: "Juan habiendo sido siempre uno de los mejores alumnos, se echa en las petacas y lo reprueban $[. .$.$] . Él piensa: para qué voy a estudiar con tantos doctores vendiendo$ cualquier maricada o manejando taxi, ni que fuera el más güevón” (p.113). En el nuevo sistema de valores de Juan, el conocimiento no es importante. La novela expresa esta idea cuando él decide quemar sus libros y cuadernos.

¡Para qué esto! Entre las evoluciones de la llamarada, se ve en un carro último modelo por las calles de Belén, o en un apartamento donde ofrece fiestas como los jóvenes de las películas gringas. Se imagina en un palacio, tirado en un diván, rodeado de mujeres desnudas abanicándolo mientras le dan a beber licor con sus propias bocas, o en un yate de lujo en las costas de Cartagena (p. II)).

Aunque Juan ingresa a la estructura del narcotráfico como "cocinero", lo que lo va a definir en el mundo de la ilegalidad será convertirse en un “jalador” de carros. Así, Juan representa un nuevo actor social que está por debajo del narcotraficante en la "pirámide" delincuencial, y a quien este mira con desprecio: "Para Capeto los jaladores de carros pertenecen a una estirpe degradada, leprosos del mundo de los negocios, algo así como una clase baja cuyo contacto debe evitarse so pena de quedar contagiado" (p. 204). Juan es una subcultura del narcotráfico, ente parasitario que ha eclosionado por el crecimiento de la drogadicción de los jóvenes -especialmente, por el consumo del bazuco-y por la pérdida del valor del trabajo honrado.

Hacia mediados de los 8o's [sic] había pues, en Medellín, grupos de "oficinas", bandas ligadas de cerca al cartel de las drogas, bandas de secuestradores, de haladores de carros, de asaltantes bancarios y, lo que más grave sería a la postre, un sinnúmero de bandas menores, sin mayor dotación de armas y sin vínculos con los narcos, dedicados al robo de tiendas, residencias, vehículos de toda clase y transeúntes en los barrios: las bandas de "Chichipatos" (Ceballos, 2000, p. 386 ). 
Igual que a Juan, a Adriana la seduce la holgada vida de su hermano Capeto: "Lo rico de la vida sería tener plata. Al pensar en lo rico de la vida ve montones de joyas, montones de ropa, montones de carros nuevos" (Porras, 2000, p. 120). Por ello, rápidamente decide dejar de estudiar: "Adriana se antoja de dejar los estudios. ¿Para qué ser profesional? Recuerda un chiste que le había servido de argumento a Juan: Aviso clasificado: se necesita ingeniero con bicicleta" (p. 120), y aunque no escoge el camino de la ilegalidad, se beneficiará del narcotráfico al irse a vivir con Óscar, un mafioso que trabaja con Capeto:

Óscar sonsaca a Adriana de la casa. - Aquí se la traeré enterita señora. Doña Luzmila nunca está de acuerdo, pero la situación supera sus fuerzas para oponerle resistencia de verdad; para hacerlo, requeriría de una autoridad ya inexistente en ella o a la cual, si la poseyera, sería incapaz de ejercer (p. 129).

El actor social que representa Adriana es el de la sociedad que se benefició abiertamente y sin conflictos morales del dinero del narcotráfico — que como en el caso del propio personaje corresponde a las esposas y viudas de los narcotraficantes-, pero no ingresa a las estructuras criminales.

En síntesis, la inmersión en el mundo del narcotráfico de Capeto cambia la estructura jerárquica de la familia, supone una sustitución de los valores en los que se cimentaba el núcleo familiar y constituye una clara metáfora de la forma en la que los actores sociales se relacionaron con el narcotráfico en la sociedad referida. En la siguiente etapa se reconstruye el devenir de los personajes para saber la evaluación de mundo que constituye la novela y la apuesta ética que subyace a dicho proyecto estético.

\section{Consecuencias de la inmersión en el narcotráfico: castigo y arrepentimiento}

En esta etapa se puede identificar el castigo que acaece en la novela a cada uno de los miembros de la familia González por su participación o connivencia con el narcotráfico. Sabemos de la muerte de Luzmila por la visita que su hija le hace a su tumba: "Estaciona el coche a un lado de la tumba de su madre, se arrodilla sobre el mármol y con una mano lo limpia de tierra, pajas y hojas secas" (Porras, 2000, p. 241). Por otra parte, el padre se ha entregado al alcohol y se desinteresa por la suerte de su familia: 
Don Genaro está sentado en un sillón, ante una botella de aguardiente a medio consumir, una jarra de agua, una copa y un vaso sobre la mesa de centro; su hijo entra afanado. - iY Luzmila! - , lo detiene la imagen de su padre bebido. Responde con un movimiento de cabeza que significa: Ahí está en la cama. Capeto se encamina al cuarto de su madre, el padre le hace un gesto de fastidio, apura un trago, con dificultad se incorpora, sale a la calle y camina por la acera. A los veinte o treinta metros ve acercarse una patrulla policial y detrás dos camionetas cuyos ocupantes, cuatro o cinco en cada una, lo analizan. Los ve detenerse cerca de su casa y comprende a qué han ido. Se devuelve cinco o seis pasos, se detiene. ¿Qué puedo hacer yo? Nada. Se aleja con la actitud de quien no le importa cuanto suceda (p. 250).

El gesto de fastidio hacia Capeto y el hecho de que no le haya avisado su próxima captura indican la ruptura del vínculo emocional del padre hacia el hijo y, por extensión, hacia su familia. Esta escena concluye con la captura de Capeto unos minutos después: "A los diez minutos sale Capeto, tan afanado como al llegar, mas, al abrir la puerta de su carro varios hombres armados lo detienen. — ¿Quieto!- - (p. 250); Juan, por su parte, es herido y queda en silla de ruedas: “-¿Qué pasó? - doña Luzmila ansía que esa sea una pregunta inmotivada y que le contesten Nada, nada... - Juan está muerto- dice, como si revelara un secreto-... No. Sólo va a quedar inválido- le advierte Capeto (pp. 227-228); Adriana, a su vez, termina viuda del mafioso amigo de su hermano: "Si tu papi estuviera aquí para verte. ¿Te le reirías así, cierto? ¿Cierto, mocosa divina? (Se santigua). O la abuela. (Mira por la ventana de la cocina, suspira)" (p. 48).

En concordancia con lo anterior, en esta etapa se presentan al lector las consecuencias aciagas del narcotráfico sobre cada miembro de la familia González. A través de la clave de la sustitución metafórica es posible equiparar el descalabro de la familia González con el de la sociedad antioqueña de la década de los 80 . Incluso el padre, que representa la sociedad que rechaza la economía derivada de la droga, es "castigado" por no ofrecer una vigorosa resistencia, dado que no hace frente cuando el dinero del negocio ilícito ingresa a su casa, disolviendo rápidamente los códigos, los valores y las lógicas en las que se soportaba la estructura de la familia. Con las resoluciones vitales de los personajes, el texto expresa su valoración sobre el narcotráfico: todos los actores de la estructura social antioqueña son culpables por permitir su ingreso y diseminación en la sociedad. 
Después de que la familia cae en desgracia, viene la etapa de arrepentimiento. Esta etapa se desarrolla a través de la inclusión de dos instancias narrativas en la novela que generan anacronías, en la medida en que le anticipan al lector lo que va a ocurrir con la familia González cuando los efectos del narcotráfico sean devastadores para cada uno de sus miembros. En una instancia narrativa, el narrador es Capeto, y en la otra, la narradora es Adriana. A través del uso del monólogo, ambos personajes lamentan la suerte que han tenido en la vida. Dos puntos en común se pueden distinguir en sus discursos. Por un lado, está la certeza de que el dinero no reverberó en felicidad. Adriana, desde su apartamento de madre soltera, dice a su hija de pocos meses de nacida: “¡No todo en la vida es plata! ¡A la hora que vengo a pensar en eso! A uno los consejos le entran por un oído y le salen por el otro” (p. 50). Por su parte, Capeto, desde la cárcel, piensa:

Este reloj debe chillar aquí, entre tanta pobreza. El más rico de todos. Valiente gracia ser el más rico. No. Lo decía Pambelé: "Es mejor ser rico que pobre" Tronco'e frase ¿ंcuándo uno deja de ser rico? No, mejor ¿̇cuándo uno deja de ser pobre? Pobre pero honrado. Pobre pero de buen gusto (p. 98).

El otro punto común es el reconocimiento de que otro hubiese sido el destino de la familia de haberse tomado el camino de la educación. Capeto reflexiona: "Si hubiera empezado una carrera, Juan me hubiera seguido. Y Adriana. Todos habrían sido profesionales” (p. 245). Así mismo, piensa: “Quiénes terminarían en la universidad? Tendrán su puesto en una empresa, casados, con hijos. Nada de fútbol en la Unidad Deportiva, ni de básquetbol, nada de desafíos contra Los Alpes [...] Feos pero felices. Feos pero tranquilos. Feos pero libres" (p. 98).

Adriana, en el mismo sentido, se lamenta: "Si no hubiera sido por Capeto. Cómo sería la vida todavía todos empacando pasas. No. Todos habríamos estudiado. Yo habría sido... Qué sería lo que me gustaba a mí. A ellos, medicina” (p. 73); “Tan raro Juan. ¡Qué le cuesta! Como si escribir cartas fuera muy difícil. Si yo hubiera estudiado. Uno de joven es muy loco" (p. 48).

Como vemos, el contraste entre la instancia narrativa que inicia la novela, en la que el narrador omnisciente y heterodiegético cuenta lo que va pasando con la 
familia González en su inclusión en el narcotráfico, y las instancias narrativas en las que Capeto y Adriana se lamentan del destino familiar, genera una perspectiva sobre los efectos del narcotráfico en la familia González. En esta etapa, el arrepentimiento de los personajes termina de cimentar la "moraleja" que atraviesa la novela: hay que honrar el esfuerzo asociado al trabajo y al estudio, pues la inmersión en el mundo del narcotráfico corroe axiológicamente a los sujetos, y el dinero que de este se deriva corrompe los valores fundamentales para una sociedad. Es, pues, preferible ser toda la vida pobre a hacer fortuna en el narcotráfico. Hay que apostarle, aun con las dificultades sociales referidas, al estudio y al esfuerzo personal como mecanismos para la promoción social.

\section{Hacia una ética de la representación: el punto de vista de Hijos de la nieve}

Al igual que Adriana y Juan, muchos jóvenes de la época se regodearon con la imagen de Pablo Escobar. El "patrón" se erigió en una figura de proporciones épicas que moldeó sus aspiraciones vitales. Sus movimientos y jugadas se convirtieron en leyenda para los jóvenes de las barriadas de Medellín, tal y como se presenta en la novela:

Pablo esto, Pablo lo otro. En cierta manera, las amigas y los amigos de Adriana y Juan desean disfrutar su existencia a la sombra de un hombre como Pablo Escobar, ser sus preferidos, tenerlo de ángel de la guarda, de Robin Hood; para ellos, en la figura del mayor de los González y sus amigos bebedores de whisky y propietarios de carros bacanos, nuevecitos, florece esa posibilidad (Porras, 2000, p. 55 ).

En Juan, Adriana y sus amigos, que representan la ciudadanía joven que ve con buenos ojos el narcotráfico, se observa la construcción de nuevos referentes morales asociados al valor del dinero y al atajismo. En este sentido, considero que el lector de Hijos de la nieve, además de presenciar la pérdida de valores sobre los que se cimentaba su conciencia de mundo, el proceso de degradación axiológica de Capeto por la experiencia de la violencia, ve cómo en su propio hundimiento arrastra a su familia hacia a la catástrofe. 
El relato construye un punto de vista que, en clave alegórica, endilga la responsabilidad de la destrucción del tejido social antioqueño al narcotráfico, que permea al conjunto de actores de la sociedad y disuelve su estructura social más profunda: la familia. La sanción compromete tanto a parte de la sociedad tradicional antioqueña que apenas se opuso moralmente y aceptó el dinero ilícito de la droga para aliviar la difícil situación económica como a aquella otra cuota que no vio con buenos ojos el origen del dinero, pero no lo rechazó de manera enérgica. De la misma manera, el relato sanciona a la sociedad joven de los barrios populares que vio en el narcotráfico una posibilidad de promoción social y de acceso a bienes de lujo, y que en consecuencia renunció al trabajo y al esfuerzo como camino de superación social. De esta manera, Hijos de la nieve señala con el índice a la sociedad entera: del descalabro del narcotráfico del que aún no podemos salir, todos somos responsables. En este sentido, a través del juego alegórico entre nieve y cocaína, el texto señala que toda la ciudad fue cubierta por la droga, como si se tratara de una ventisca. En el siguiente pasaje se expresa la idea.

Tan maluca esta ciudad, tan peligrosa, se roban un hueco. Mentira, no sé por qué tiene tan mala fama. Medellín es la ciudad de la eterna primavera. ¿Cómo serán las estaciones? Cuando Jennifer Carolina crezca la llevo a Estados Unidos a conocer la nieve para que haga muñecos como en las películas. Somos hijos de la nieve. Jennifer Carolina es hija de la nieve. Las bobadas que digo. ¿Por qué llamarán a eso nieve y perico? (Porras, 2000, p. 207).

Para concluir, quiero señalar que la novela no ofrece una interpretación sobre la realidad que pueda considerarse paralizante o desesperanzadora para el lector - como otras producciones culturales sobre el mismo tema-, pues no celebra la figura del narcotraficante (mirada apologética) ni tampoco cierra la posibilidad de superación del narcotráfico acusando condiciones étnicas o genéticas del antioqueño (mirada fatalista). Considero que, por el contrario, la narración de las consecuencias nefastas del narcotráfico en las proyecciones vitales de los personajes y la insistencia en señalar ese otro destino que pudo haber tenido la familia González sin la inserción de Capeto en la estructura delictiva invitan a una praxis vital que dignifique valores como el esfuerzo y la honestidad, que son ejes transformadores de la sociedad. 


\section{Referencias bibliográficas}

Bajtín, M. (1994). El método formal en los estudios literarios: introducción crítica a una poética sociológica. Madrid: Alianza.

Ceballos, R. (2000). Violencia reciente en Medellín: una aproximación a los actores. Bulletin de l'Institut français d'études andines 29 (3), pp. 381-401.

Fonseca, A. (2009). Cuando llovió dinero en Macondo: literatura y narcotráfico en Colombia y México (tesis de doctorado). Universidad de Kansas.

Gutiérrez de Pineda, V. (1994). La familia en Colombia. Trasfondo bistórico. Medellín: Ministerio de Cultura, Universidad de Antioquia.

Osorio, Ó. (2014). La novela del narcotráfico en Colombia. Cali: Universidad del Valle.

Palacios, M. (2002). Entre la legitimidad y la violencia: Colombia 1875-1994. Bogotá: Editorial Norma.

Porras, J. L. (2000). Hijos de la nieve. Bogotá: Planeta.

Reina Echeverry, M. (1992). La economía del narcotráfico en la subregión andina. En El narcotráfico en la región andina (pp. 45-78). Bogotá: Parlamento Andino.

Salazar, A. y Jaramillo, A. M. (1992). Medellín: las subculturas del narcotráfico. Bogotá: Cinep.

Salazar, A. (2012). Pablo Escobar, el patrón del mal (La parábola de Pablo). Bogotá: Aguilar.

Uribe, A. C. (2018). Medellín a oscuras: ética antioqueña y narcotráfico. Medellín: Universidad Pontificia Bolivariana.

Vallejo, F. (1994). La virgen de los sicarios. Bogotá: Alfaguara.

Walde, E. von der (2000). La sicaresca colombiana. Narrar la violencia en América Latina. Nueva Sociedad 170, pp. 220-226. 